Angelina Raičković

Arheološki institut Beograd

Saša Redžić

Arheološki institut Beograd

Bebina Milovanović

Arheološki institut Beograd

UDK 904:738.8(497.11)"01"

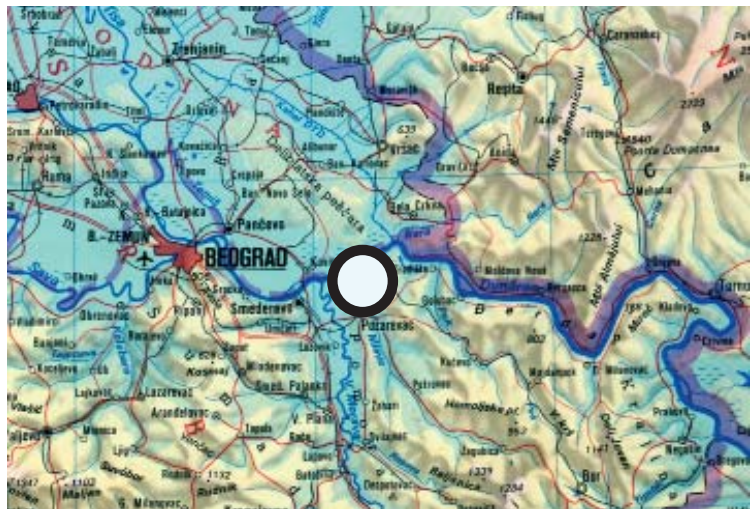

Viminacium, Stari Kostolac, Srbija

LAT 44 44' 09" / LONG $21^{\circ} 12^{\prime} 42^{\prime \prime}$

\title{
POSUDE SA APLICIRANIM ZMIJAMA IZ ZANATSKOG CENTRA
}

\begin{abstract}
ABSTRAKT
Na prostoru između keramičkih iopekarskih pećiZanatskog centra, u slojušuta, među mnogobrojnim fragmentima građevinskog materijala pronađeni su i brojni fragmenti različitih posuda, od kojih je nekoliko sa apliciranim zmijama. Fragmenti pripadaju većim loncima, sa horizontalno izvučenim obodom i cilindričnim vratom čiji se trbuh lomi ka prstenasto profilisanoj stopi. Ovakve posude se vezuju za različita božanstva i njihove kultove, a na ovom prostoru se datuju u period od sredine II veka. Nalazimo ih na različitim lokacijama, kako na samom Viminacijumu, tako i širom provincije Gornje Mezije, dokje njihova najveća brojnost konstatovana na prostoru provincije Dakije.
\end{abstract}

KLJUČnE REČI: Zanatski Centar, ViminaCiJum, APLiciRane ZMiJe, POSUde, KUltovi, Mitra, Sol, LIBER

Prilikom nivelisanja terena i postavljanja kvadratne mreže za istraživanje lokacije Zanatskog centra na Viminacijumu naišlo se i na velike površine pod šutom. Njega su činili delovi opeka, tegula i imbreksa, grumenovi zapečene zemlje sa primesama gari i fragmenti različitih keramičkih i staklenih posuda. Iz keramičkog materijala Zanatskog centra svojim posebnim karakteristikama izdvojili su se fragmenti posuda sa apliciranim zmijama koji su nađeni u dva kvadrata postavljene kvadratne mreže (Plan I). Fragmenti posude otkriveni na prostoru između kvadrata br. XXXIX i XLI nalazili su se ispod sloja šuta, u sloju koji je uz fragmente drugog keramičkog materijala sadržavao i delove životinjskih kostiju - udovi govečeta. U neposrednoj blizini pronađena i ljudska lobanja kao i srebrni novac Antonija Pija. Drugi fragmenti sa apliciranom zmijom nađeni su u kvadratu br. XLIV. U ovom kvadratu se po uklanjanju slojeva šuta ukazao ukop sa tamnomrkom zemljom dimenzija $9,80 \times 4,00 \mathrm{~m}$. U njegovom severnom delu konstatovano je izuzetno mnogo keramičkog materijala, ${ }^{1}$ među kojim i fragmenti imbreksa sa pečatom LEG VII CL i fragmenti životinjskih kostiju sa kojima su bili pomešani i fragmenti posude sa apliciranom zmijom.

1. Keramičke posude otkrivene u ovim celinama predstavljene su na grafikonu br. 1. Za detaljnije o posudama iz ovih celina pogledati Raičković 2005, 17 - 53. 
Ova vrsta posuda rasprostranjena je po zapadnorimskim provincijama i odlikuje se različitim specifičnostima. Tzv. zmijske posude proizvode se od gline različitog kvaliteta i različite boje pečenja. Spoljna površina je najčešće bojena tonovima mrkocrvene boje do potpuno mrke, a izuzetno retko je maslinastozeleno gleđosana. ${ }^{1} \mathrm{Ug}$ lavnom se javljaju na velikim posudama - loncima i krčazima. Često su to posude sa dve ili tri drške, pa aplicirana zmija, jedna ili više, ide po obodu posude, obmotava se oko drški sa glavom koja leži na obodu, ili je cela aplicirana cik-cak u gornjem delu posude. Glava zmije obično je sumarno urađena, dok kožu zmije imitiraju različito izvedeni i grupisani urezi i ubodi u vidu crtica ili kružića. Uobičajena pojava kod ovih posuda je da se javljaju u kombinaciji sa pečatnom dekoracijom, ili sa medaljonima koji su rađeni u kalupu pa naknadno aplicirani na površinu. Mogu se javiti i u kombinaciji sa ukrašavanjem koje je izvedeno urezivanjem geometrijskih ornamenata. Javljaju se i u kombinaciji sa odgovarajućom reljefnom dekoracijom - antropomorfne, zoomorfne ili vegetabilne predstave. Ove posude su osobene kroz duži vremenski period. Razlike u vrsti korišćene gline i karakteristike u izradi i dekoraciji rezultat su različitih proizvodnih centara i lokalnih uticaja, te povezivanja sa različitim božanstvima.

Fragmenti posuda prona-đenih u krugu Zanatskog centra (T. I i II) odgovaraju sličnim posudama pronađenim kako na teritoriji provincije Gornje Mezije, ${ }^{2}$ tako i onim nađenim na području provincije Dakije. ${ }^{3}$ Radi se o fragmentima većeg lonca, debelih zidova, rađenog od srednje prečišćene gline crvene boje pečenja i bojene spoljne površine crvenom bojom (boja pečenja: Mansell 5yr-6/8). Očuvani su i fragmenti trakaste drške na kojoj je takođe aplicirana zmija. Medaljon je rađen u kalupu i predstavlja mušku figuru koja stoji i u desnoj ruci drži kantaros, na desnoj strani je deo vinove loze sa plodovima, a

1. Cvjetićanin 2001, 37 - 40.

2. Cvjetićanin 2001, 93-104; Nikolić-Đorđević 1997 , 120, sl. 46.

3. Bolindet 1993, 123-141.

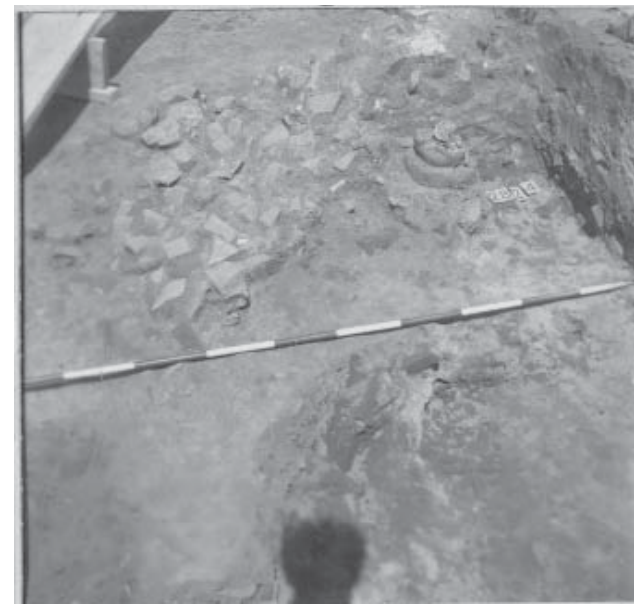

Slika 1. Sloj šuta sa fragmentima posuda i životinjskim kostima

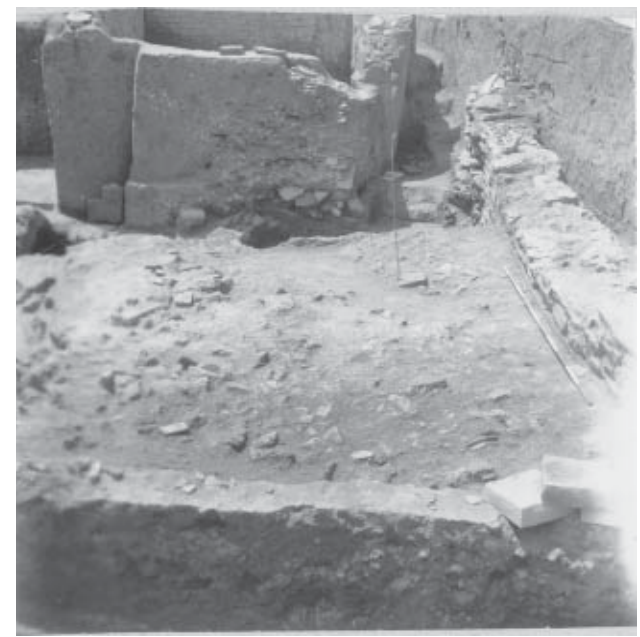

Slika 2. Sloj sa fragmentima posuda, opeka i životinjskih kostiju

pored noge figure muškarca su psi (T. II, sl. 3). Deo gde bi trebalo da se nalazi glava i levo rame nedostaju. Telo zmije je ukrašeno poprečnim paralenim nizovima izvedenim tehnikom ubadanja. Glava zmije je sumarno obrađena i nalazi se na obodu posude. Posebno je zanimljiva muška figura u medaljonu. Analogije koje se mogu naći za ovakve posude ukazuju na njihovo povezivanje sa kultovima bogova plodnosti što se može primeniti i na posude iz Zanatskog centra. Povezivanje sa božanstvom koje ukazuje na kult plodnosti preko vinove loze i preko kantarosa u ruci, te psima koji stoje kraj nogu ukazuju kako na Dionisa, tako i na lokalnu varijantu Libera čiji je kult $i$ inače posvedočen na prostoru Viminacijuma. ${ }^{4}$

4. Spasić-Đurić 2002, 173. 


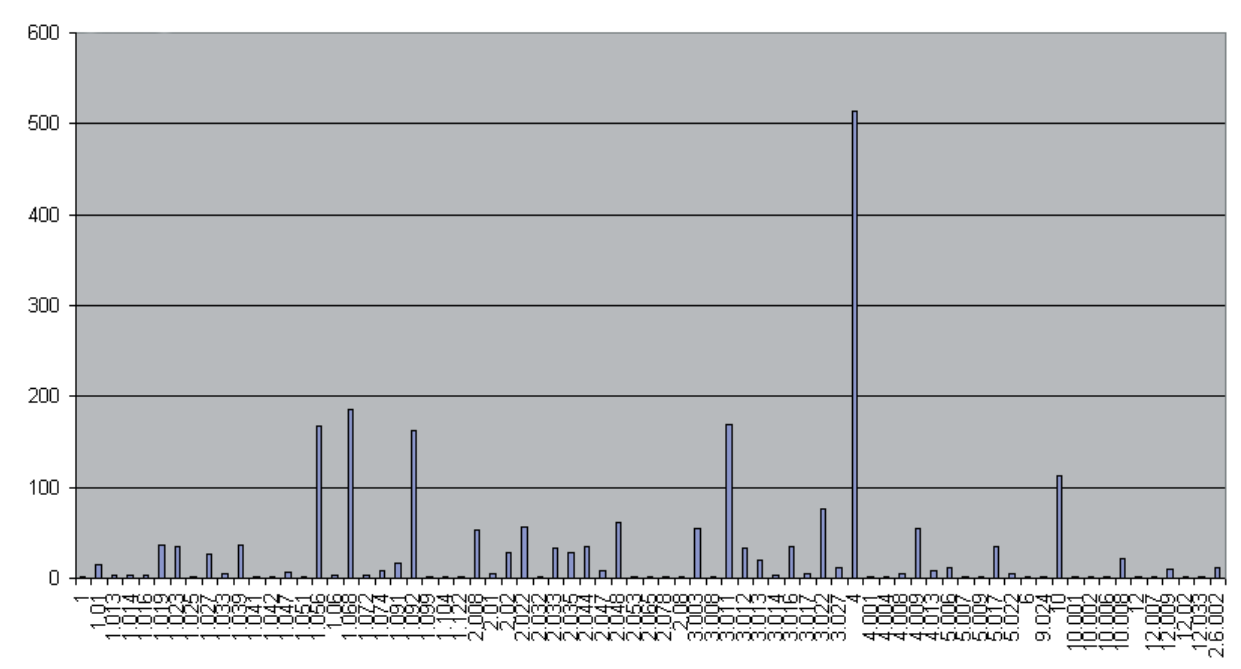

Grafikon sa oblicima posuda koje se javljaju u sloju gde su konstatovani fragmenti posuda sa apliciranim zmijama na lokaciji Zanatskog centra iz Viminacijuma

Posude sa apliciranom zmijom kao dekoracijom smatraju se sakralnim posudama i najviše se vezuju za Mitrin kult kao i za kultove drugih istočnih božanstava u prvom redu Sabazija. Noviji autori vezuju ove posude za kult Libera i Libere. ${ }^{5}$ Na mestima gde se ove posude javljaju opredeljene su i kao posude korišćene u funeralnim kultovima sa indirektnim vezama sa Sabazijevim i Dionizijevim krugom. Savremena gledišta su ta, da su ih koristili i u kućnim kultovima, jer je zmija još od ranije bila smatrana za zaštitnicu kuće i porodice. Pažnja se mora obratiti i na lokalne, domorodačke uticaje u dekoraciji ovih posuda, ali i naglasiti uticaj istočnih božanstava. Naime, vojnici regrutovani na Istoku donose svoje kultove koji se mešaju i delimično asimiliraju sa rimskim. Uz specifične lokalne uticaje stvaraju se nova božanstva koja svoj odraz dobijaju u dekoraciji posuda. Tako se među rimskim bogovima pojavljuje i ne mali broj onih koji imaju istočno poreklo, a za koje se vezuje poštovanje zmije. Jedan od njih je i Liber, bog plodnosti, polja, livada i stoke, ali i podzemlja i svih bogatstava koje ono krije. On je i zaštitnik vina i vinove loze sa istim atributima kao i Dionis. Liber se vezuje za kultove prirode i božanstvo je vegetacije i plodnosti.

U slučaju fragmenata sa apliciranom zmijom iz zanatskog centra potrebno je obratiti posebnu 5. Gassner 1990, 654 . pažnju na ostali materijal među kojem su ovi fragmenti otkriveni. Pažnju privlače fragmenti kostiju opredeljeni kao ostaci govečeta, koji govore u prilog obredima povezanim sa poštovanjem persijskih božanstava. Zmija kao simbol prati Mitru u svim predstavama, bilo da se pojavljuje kod njegovog kipa ili na zadnjoj strani oltarske ploče. Jedna od pretpostavki je da se ova posuda mogla upotrebiti u svešteničkom obredu koji su sledili Mitrinom žrtvovanju bika. Iste ovakve posude - lonci sa tri drške oko kojih se uvija aplicirana zmija, pronađeni su u Mitreju na Gornjem Bregu kod Ptuja. ${ }^{6}$ Ukrašene su lozicom grožđa sa listovima i plodovima hrasta, žirovima. Vinova loza i grožđe predstavljeno je u našem slučaju u medaljonu koji je bio apliciran na trbuh fragmenta posude gde je zmijsko telo obmotavalo trbuh posude, uzdizalo se preko drške, sa glavom koja je završavala na obodu posude. Pojava vinove loze i grožđa nije baš česta u Mitrinom kultu, pa se to može pripisati mešanju uticaja sa drugim božanstvima. U mitraizmu se stapaju drugi antički bogovi: Merkur, Venera, Mars, Jupiter, Saturn, Sol i Luna. Ono što podupire odluku da se zmijske posude prvenstveno trebaju vezivati za Mitrin kult jesu i ostali otkriveni fragmenti takvih posuda, gde su u medaljonima apliciranim na trbusima lonaca predstavljeni bikovi. Posude sa 6. Lamut 2004, 113. 


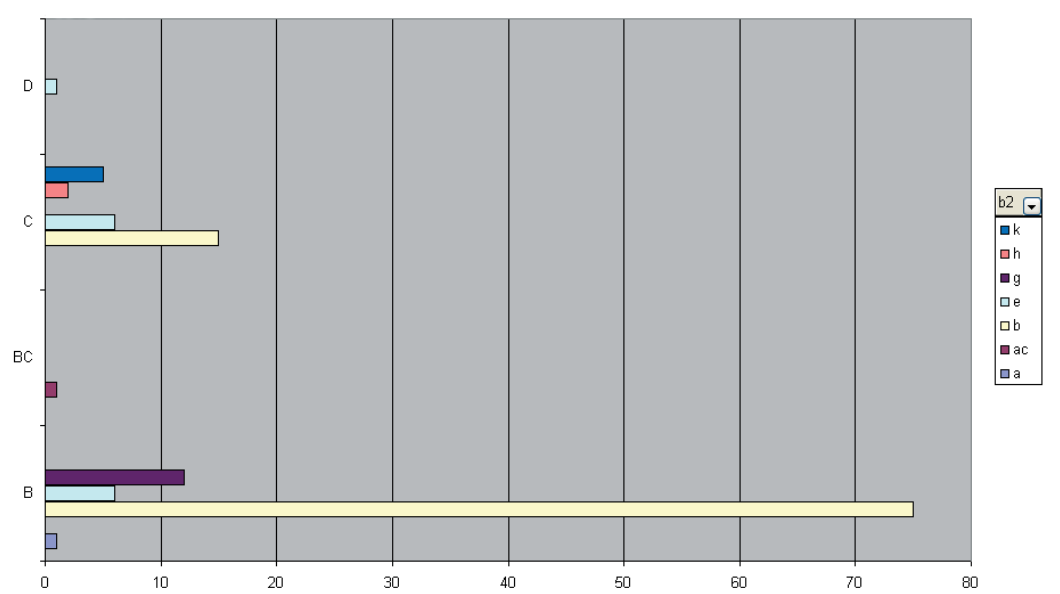

apliciranim zmijama nađene su na više lokacija na Viminacijumu među kojima i na nekropoli Pećine. Zanatski centar je, u stvari, deo nekropole Pećine, te ne čudi što su u njegovoj neposrednoj blizini nađeni brojni različiti fragmenti posuda sa apliciranim zmijama sa istim tehnološkim karakteristikama. Sve su posude rađene od srednje prečišćene gline crvene boje pečenja, sa tom razlikom da im je spoljašnja površina ili neobrađena ili bojena tonovima crvene boje, gde se opet razlikuje kvalitet premaza od slabog, koji se lako otire, do izuzetno kvalitetnog i tzv. firnisa crvenkaste boje. Posebno je zanimljivo da su ovi oblici posuda u stvari isti kao oni iz Zanatskog centra. Radi se, naime, o velikim loncima sa horizontalno izvučenim obodom, sa dve ili tri drške, cilindričnim vratom koji se lomi ka trbuhu na prstenasto profilisanoj stopi (tip II/48). ${ }^{1}$ Deo cilindričnog vrata je ukrašen utisnutim vegetabilnim motivima gusto raspoređenim u više redova. Među motivima koji se mogu identifikovati na reljefnim predstavama prepoznaju se biljke kao što su palma, akant, lovor i hrast. Među oblicima na kojima se još javljaju aplicirane zmije izdvajaju se i velike zdele na čijim drškama su sumarno izvedene zmijske glave.

Proizvodni centar ovih posuda mogli bismo pretpostaviti na Viminacijumu jer su ove posude nađene na nekoliko mesta u krugu istraženog dela Zanatskog centra, a takođe i na ostalim istraživanim

1. Raičković 2005, T. VI/69 lokacijama. Na ovakav zaključak navodi to što se ovakve posude ne javaljaju na teritoriji provincije Dalmacije, dok ih na prostoru Gornje Mezije i Dakije 2 ima u velikom broju. Jedna od pretpostavljenih radionica nalazila bi se u Drobeti.

Iz pisanih izvora potkrepljenih dosadašnjim arheološkim istraživanjima Viminacijuma, saznajemo da su u gradu i logoru boravili vojnici sa Istoka koji su sa sobom doneli svoje kultove i na ovom prostoru nastavili da ih poštuju. To se, pre svih, odnosi na Mitrin kult koji u svojim različitim stepenima posvećivanja sadrži i obrede inicijacije pri kojima, pretpostavljamo da su ove posude i bile upotrebljavane. Za to nemamo direktnih potvrda sem analogija sa drugih lokaliteta na kojima su ovakve posude pronađene u mitrejima. U svakom slučaju, smatramo da ove posude treba svrstati u posude korišćene pri vršenju raznih kultova. Njihova proizvodnja na samom Viminacijumu počinje sredinom II veka.

\section{RESUME}

\section{Vessels With Snake-like Applications From Viminacium Production Centre}

Vessels with snake-like applications were fount at several locations at Viminacium. Here, only those found within the area of the manufac-

2. Popilian 1976, Pl. XXVII-XXX/290-303; Popilian 1997, T. XVI-XVII/1-5. 
Arheologija i prirodne nauke

turing centre are presented. They build a smaller, but not less important number of shapes and fragments found. Such vessels are actually big pots with medallions with different scenes on their bellies, around which a snake is applied, who also stretches around the handles and whose head is placed on the horizontally formed rim. The symbol of a snake is connected to various deities and their cults, while in this paper the Mithraistic cult was given priority. The area in which these fragments were found was dated from the middle of $2^{\text {nd }}$ throughout the whole $3^{\text {rd }}$ century according to small finds. The production of such vessels within the manufacturing center can also be placed into this chronological frame.

Translated by M. Tapavički-Ilić

\section{BIBLIOGRAFIJA}

\section{Bolindet 1993}

V. Bolindet, Considération sur l'attribution des vases de Dacie romaine décorés de serpentr appliqués, Ephemeris Napocensis III, Cluj-Napoca 1993, 123 -141 .

\section{Cermanović-Kuzmanović, Srejović 1992}

A. Cermanović-Kuzmanović, D. Srejović, Leksikon religija i mitova drevne Evrope, Beograd 1992.

\section{Cvjetićanin 2001}

T. Cvjetićanin, Gleđosana keramika Gornje Mezije, Beograd 2001.

\section{Cvjetićanin 2001}

T. Cvjetićanin, Snake Vessels from Diana, Die Archäologie und Geschichte der Region des Eisernen tores zwischen 106-275 N. Chr., Bucureşti 2001, 93 -104 .

\section{Gassner 1990}

V. Gassner, Schlangengefässe aus Carnuntum, $A k$ ten des 14. Internationalen Limeskongres 1986 in Carnuntum, Wien 1990, 651 - 656.

\section{2 (2006)}

\section{Ivanišević, Nikolić-Đorđević 1997}

V. Ivanišević, S. Nikolić-Đorđević, Novi tragovi antičkih fortifikacija u Singidunumu - lokalitet Knez Mihailova 30, Singidunum I, Beograd 1997, 65 - 150.

\section{Jordović 1995}

Č. Jordović, Grnčarski i ciglarski centar u Viminacijumu, Saopštenja XXVI, Republički zavod za zaštitu spomenika kulture, Beograd 1995, 95 - 106.

\section{Lamut 2004}

B. Lamut, Posudi z mitraično kultno simboliko iz Petovione, Rimljani: steklo, glina, kamen, Katalog za izložbu, Celje 2004, 112 - 115.

\section{Munsell 1975}

Munsell Soil Color Charts, Baltimore, Maryland 1975.

\section{Nikolić-Đorđević 2000}

S. Nikolić-Đorđević, Antička keramika Singidunuma, Singidunum II, Beograd 2000, 11 - 244.

\section{Popilian 1976}

G. Popilian, Ceramica Romana din Oltenia, Craiova 1976.

\section{Popilian 1997}

G. Popilian, Les centres de production cëramique d'Olténie, Études sur la céramique romaine et daco-romaine de la Dacie et de la Mësie Infërieure, Timişoara 1997, 7-21.

\section{Raičković 2005}

A. Raičković, Keramičke posude iz Zanatskog centra sa Viminacijuma, magistraska teza u rukopisu, Beograd 2005.

\section{Spasić-Đurić 2002}

D. Spasić-Đurić, Viminacijum glavni grad rimske provincije Gornje Mezije, Požarevac 2002. 


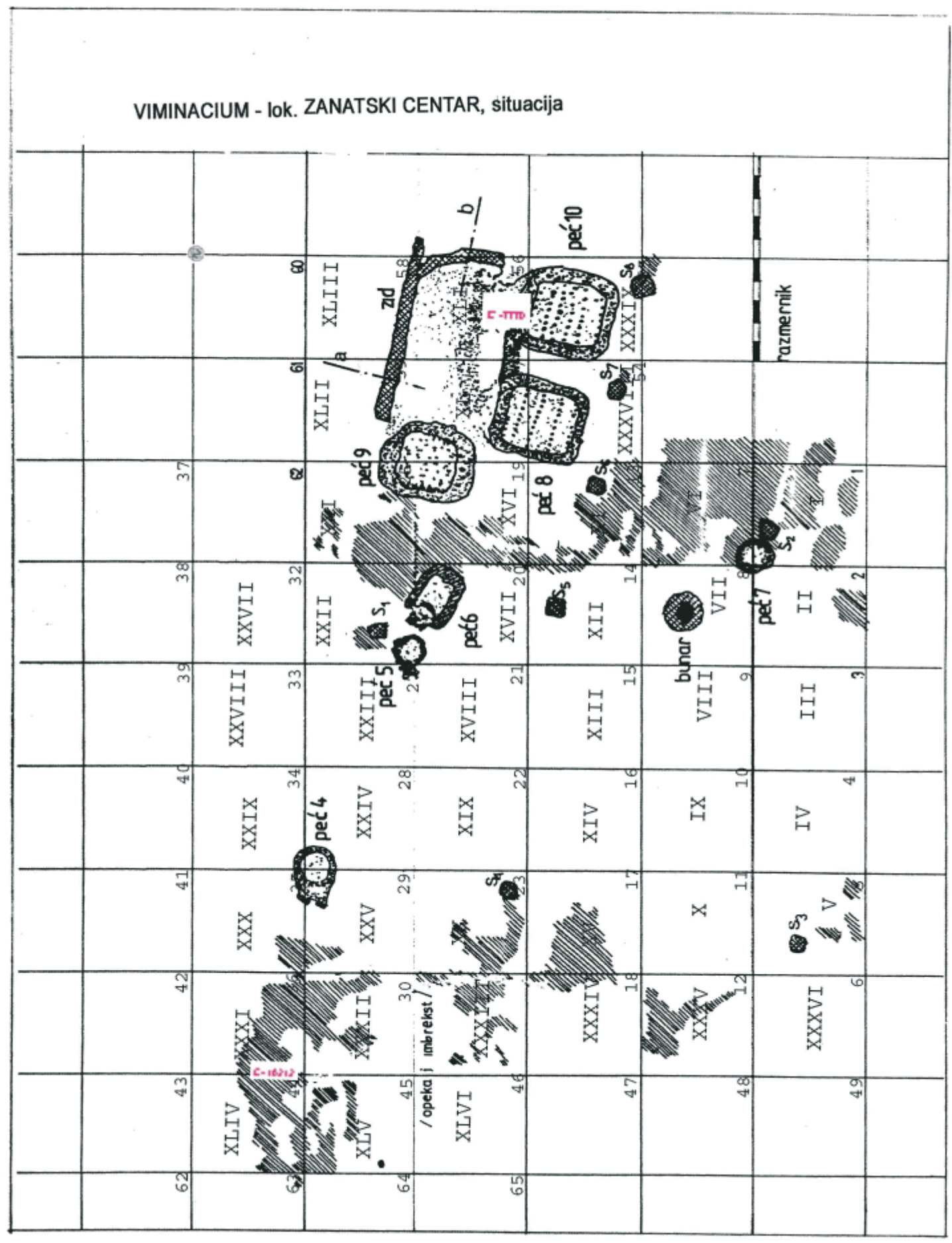

Plan I. Mesto nalaza posuda sa apliciranim zmijama u Zanatskom centru 
T. I
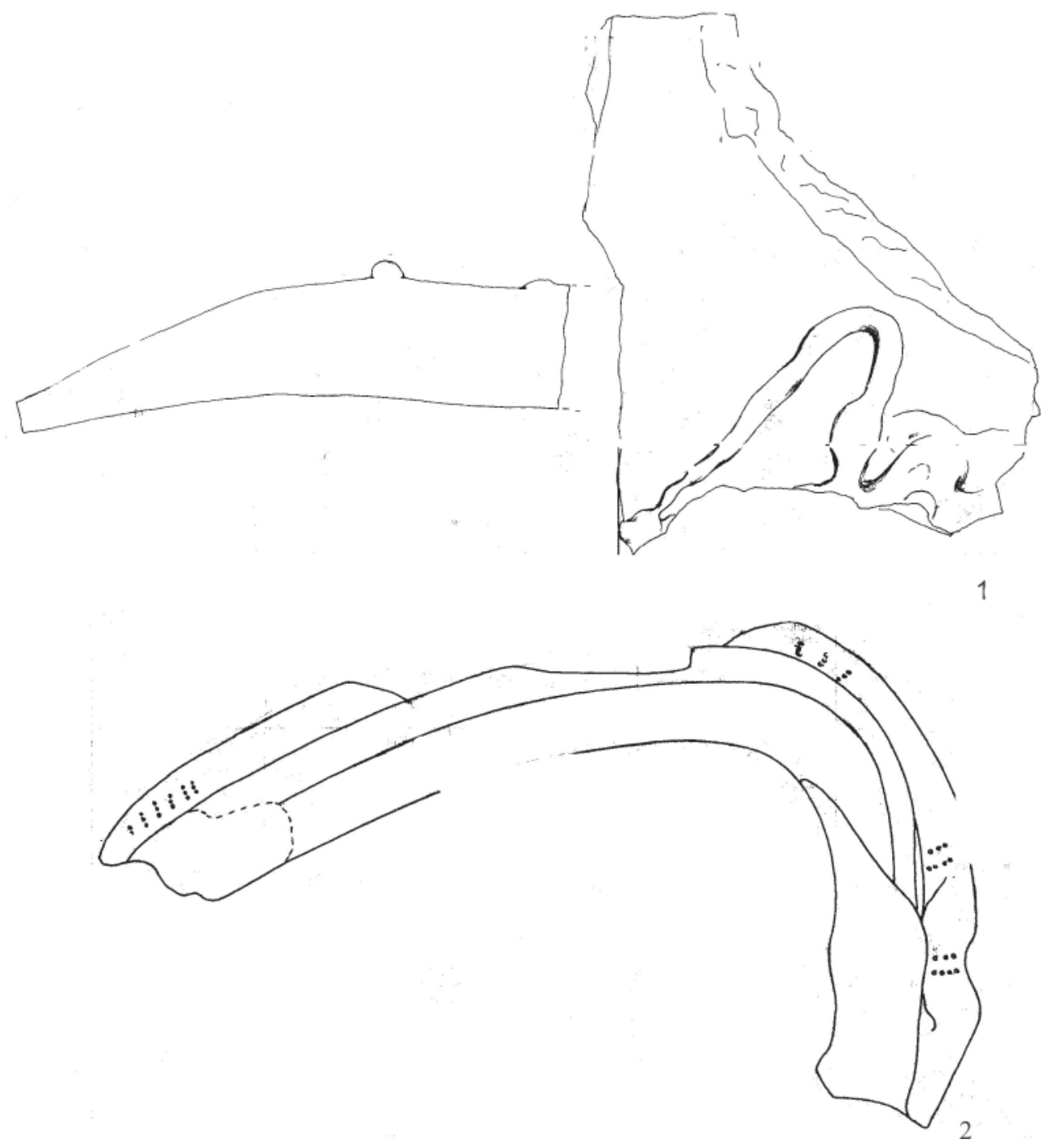

$\mathrm{R}(2: 3)$ 

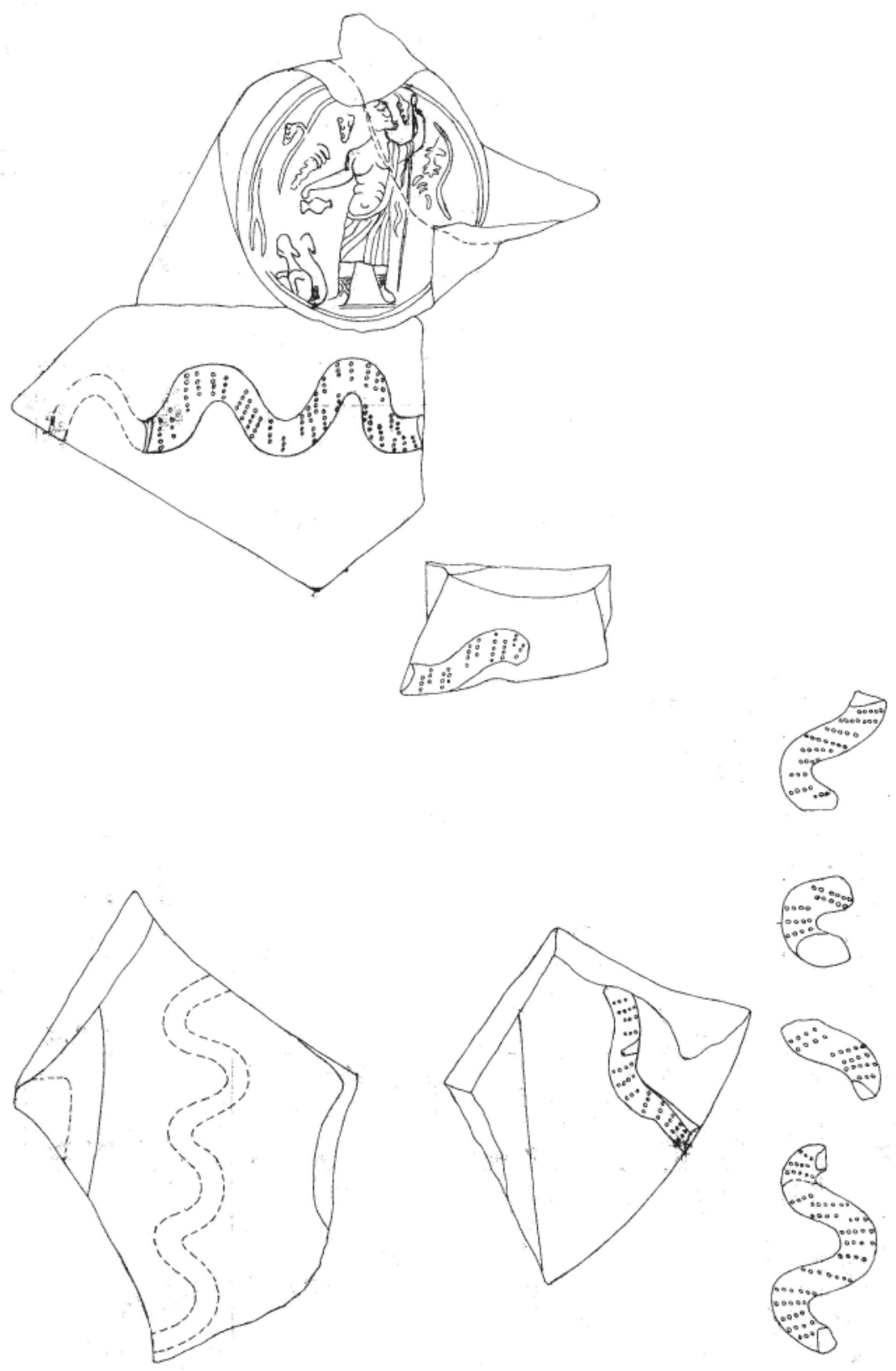

R (2:3) 